DOI 10.37882/2223-2982.2021.02-2.08

\title{
СЕМАНТИЧЕСКИЙ АСПЕКТ ГЛАГОЛОВ РЕЧИ В СОВРЕМЕННОМ АНГЛИЙСКОМ ЯЗЫКЕ
}

\section{SEMANTIC ASPECT OF SPEECH VERBS IN MODERN ENGLISH}

\section{N. Ganbarova}

Summary: In the presented article, the components of several thematic groups of English speech verbs are briefly considered, including certain subgroups. First of all, it was established that they represent an organized and complex lexico-semantic unity. However, their semantic content does not go beyond the core concepts: the meanings of speaking, telling, talking, discussing are always and invariably postulated.

Obviously, the English verbs of speech, as follows from the etymology, are directly related to speech-production. $0 \mathrm{n}$ this basis, for real linguistic analysis, we have identified four main verbs: «to say», «to tell», «to speak» and «to talk». By their outward formal features, they are similar to each other. However, the three types of periphery highlighted in the article - near, distant and extreme, depending on the degree of distance from the core of the main verb of speech - indicate their common semantic significance. Therefore, the author of the article points to a fairly wide range of components adjacent to the named central verbs.

Keywords: verbs of speech, verbal components, constituents, linguistic features, linguistic environment, linguistic units, definitions, periphery, cognitive linguistics.
Ганбарова Нурлана Эльдениз гызы

Преподаватель, Бакинский славянский университет giz.nur@bk.ru

Аннотация: В представленной статье вкратце рассмотрены компоненты нескольких тематических групп английских глаголов речи, включающие в себя и определённые подгруппы. Прежде всего установлено, что они представляют собой организованное и сложное лексико-семантическое единство. Однако их семантическое содержание не выходит за границы стержневых понятий: всегда и неизменно постулируются значения говорить, рассказывать, беседовать, дискутировать.

Очевидно, что английские глаголы речи, как следует из этимологии, связаны непосредственно с рече-производством. На этой основе для настоящего лингвистического анализа нами были выделены четыре основных глагола: «to say», «to tell», «to speak» и «to talk». По внешним формальным признакам они похожи друг на друга. Однако выделенные в статье три вида периферии - ближняя, дальняя и крайняя в зависимости от степени удалённости от ядра основного глагола речи - свидетельствуют 06 их единой семантической значимости. Поэтому автор статьи указывает на достаточно широкий спектр примыкающих к названным центральным глаголам компонентов.

Ключевые слова: глаголы речи, глагольные компоненты, конституенты, языковые признаки, языковое окружение, языковые единицы, дефиниции, периферия, когнитивная лингвистика.
$\mathrm{B}$ современной когнитивной лингвистике исследование английских глаголов речи проходит по различным направлениям. Это связано, главным образом, с тем, что русские, азербайджанские и европейские языковеды ставят индивидуальные задачи. Насколько нам удалось выяснить из трудов Камала Абдуллы, Галины Удалых, Аслана Мамедли и некоторых других, названных видных отечественных учёных отчасти интересовали синтаксические свойства русских и азербайджанских глаголов (в том числе и иноязычных речевых) в их сравнительно-сопоставительном аспекте. В России и Европе в разные годы этим вопросом занимались такие выдающиеся учёные, как Л. Ельмслев, Ш. Балли, Э. Бенвенист, В. Виноградов, В. Гумбольдт и другие. Русские и европейские лингвисты рассматривают английские речевые глаголы на функциональном уровне с позиции их лексико-грамматической семантики. Конкретизируем: о семантических свойствах настоящего класса глаголов и пойдёт речь в нашей статье.

Прежде всего, твёрдо установим, какие английские глаголы традиционно относятся к речевым. Это: «to say», «to tell», «to speak» $и$ «to talk» ${ }^{1}$. Они обозначают речевой процесс и манифестируют в той или иной степени сообщения, беседу или рассказ.

Названные исследователи разделили глаголы речи на две центральные подгруппы. В первую включают глаголы, которые не имеют дополнительных (то есть сопроводительных) характеристик и не нуждаются соответственно в пояснениях, комментариях. Другими словами, они выступают в чистом, если так дозволено выразиться, рафинированном виде. Во вторую включают глаголы, имеющие более узкую сферу употребления. Это: «express», «declare», «repeat», «narrate». Они также участвуют на равноправных началах в рече-производстве.

Современные лингвисты озабочены тем, как соотносятся английские глаголы речи с другими частями речи, знаменательными или служебными. Это необходимо выяснить с точки зрения выражения речевого процесса как такового. Ведь помимо этого процесса, эти глаголы

1 Примечание: для удобства анализа и восприятия возьмём их в инфинитивной форме. 
указывают ещё и на определенные речевые акты. Так что без учёта семантических факторов, сочетающихся с различной оценкой (эмоциональной либо без эмоциональной), неправомерно определять сферу функционального назначения интересующей нас группы глаголов. В эту оценку, в частности входят каузация, истинность, интенциональность, экспрессия и т.д.

Следуя таким путём (с учётом указанного фактора сочетаемости), учёные делят речевые глаголы на три группы:

а) непосредственно процесс говорения;

б) коммуникативный аспект настоящего процесса;

в) процесс речи, связанный с жизнедеятельностью человека.

Характерной особенностью первой группы английских глаголов речи является отсутствие самой сути высказывания и потому симптоматично, что в нём нет отражения конкретных фактов, событий или и явлений. В данном случае речь идёт исключительно о номинативном значении отдельных фраз, слов.

В отличие от группы английских глаголов речи № 1, специфической особенностью второй группы являются сами действия говорения. Очевидно, что они входят в состав темы или ремы. Следовательно, носят всесторонний характер. Однако это уже выходит за рамки статьи.

Наконец, особенностью глаголов речи третьей группы является такое обозначение действий, которые проявляют себя только с сугубо внешней стороны. Основные признаки говорения в данном случае выражают непосредственно волеизъявление.

В самом начале статьи мы назвали фамилии наиболее известных современных азербайджанских языковедов, которые обращали особое внимание на характер синтаксических конструкций. Некоторые русские и европейские учёные, отчасти занимающиеся проблемами функционирования английских глаголов речи, добавляют, что они тесно связаны с их лексико-грамматической сочетаемостью. Например, отдельные глаголы речи и инфинитив, глаголы и прямая речь, глаголы и придаточные предложения.

В свою очередь сочетания английских речевых глаголов с такими словами, как «immediately», «carefully», «strongly», «perfectly», «precisely», «easily», свидетельствуют об энергичности, внимательности, интенсивности, тщательности продуманных субъектом действий и одновременно указывающие на его активный характер. Вместе с тем при некоторых английских глаголах речи могут функционировать такие дополнительные сигнализаторы, которые иллюстрируют активную деятельность говорящего. Современные лингвисты перечисляют при этом характерологические признаки, как-то: императив, прогрессив и некоторые другие.

Ряд учёных пытаются определить преимущество такого подхода деления глаголов речи на группы и подгруппы? Например, О.Д. Дворник в автореферате своей докторской диссертации фиксирует: «Прежде всего ценность деления на группы и подгруппы по ступеням заключается в том, что тщательный анализ сочетаемости конкретно рассматриваемого речевого глагола в той или иной степени выявляет их связи с разными формами и видами других слов или же целыми выражениями в составе предложений с целью наиболее точного определения их зависимости от лексико-семантического значения речевых глаголов» [3, с.15-16].

Итак, после преамбулы приведем лексико-семантические характеристики глаголов «to say», «to tell», «to speak» и «to talk». Сущность семантики глагола «to say» состоит в передаче некоторой информации. А так называемые конституэнты, образуют синонимический ряд. Его цепочка содержит ряд дифференциальных признаков с соответствующими семантическими нюансами.

В качестве одного из конституэнтов можно назвать и глагол речи «to say», позволяющий выделить такие семантические элементы, как «словесное выражение мыслей (идей)»; «выражение мнения»; «всевозможные свидетельства, указывающие на что-либо».

Например: «One time to say you loved him...».

Семантические конституенты имеют ближнюю, дальнюю (отдалённую в трактовке некоторых учёных) и крайнюю периферии. В ближней от «to say» выделим такие семы, как «vocalize», «utter», «speak», «announce», «pronounce», «mouth». Наиболее обобщённое содержание всех их значений - это «владение устной речью». «No answer, that was to say, in any words that could be uttered in their presence, that uttered, those two martyrs».

Если конкретизировать это значение с помощью лексем «ясный», «чёткий», «отчётливый» и т.п., то в приведённый ряд, по нашему мнению, можно включить слова или словосочетания «words», «put in words», «articulate», «phrase». Само сообщение, равно как и ответ на него, как правило, предполагает некую реакцию. Это глаголы: «respond», «answer», «rejoin», «reply», «retort». Реакцию в данном случае в рамках ближней периферии характеризуют семы «дать ответ», «давать ответы», «реагировать каким-либо образом на что-то».

Вопрос и ответная реакция, по логике вещей, означают обмен некоторой информацией. Её, как производные от «to say» передают речевые глагольные инварианты «come out with», «convey», «remark», «communicate» и другие. Общедоступность информации, включая выше- 
отмеченные ответные реакции, доводят до нас глаголы речи «declare», «state», «impart», «tell» и другие. (Впрочем, о последнем глаголе речь пойдёт в нашей статье ниже).

Передача информации может носить не только явный, открытый, но и скрытый (секретный) характер. Их от «to say» выделяют глаголы дальней периферии - «let out», «reveal», «disclose», «divulge», «cry», «make known», «abroad» и «noise». Показательно, что перечисленные глаголы в речи имеют своё конкретное назначение. А именно: 1). «Передача секретной информации»; 2). Тонирование по степени громкости, выраженное антонимичными глаголами «шуметь» или «молчать». В свою очередь дальнюю периферию от «to say» составляют глаголы «whisper», «breathe» и «betray». Их особенностью является тонирование самого тихого звука, то есть «говорить тихо, неслышно» и - по нисходящей линии «шептать». Среди трёх названных глаголов речи «betray» носит дополнительный семантический оттенок, выражающийся уже не в секретности, но, напротив, - точности и достоверности информации.

Крайняя (то есть наиболее удалённая от ядра периферия) образуется посредством функционирования в речи (или в текстах) языковых единиц последующего синонимического ряда с помощью стержневого инфинитива «to say». Это такие глаголы, как «recite», «repeat», «orate», «declaim», «rehearse», «deliver», «render» и аналогичные по своей семантике. Они представлены семой «повторения, закрепления» или «официального заявления». Напротив, если утверждения нет, то в качестве альтернативной антитезы выступают глаголы речи «predict», «estimate», «speculate», «predicate», «conjecture», «hypothesize», «hazard a guess» и некоторые им подобные. Это отражение лишь предположения, гипотезы, теоретического положения, которое следует проверить.

Интересными, на наш взгляд, являются инварианты с основным глаголом речи «to say», выражающие намерение (желание) говорящего. Нередко в англоязычной литературе эти действия передаются глаголом «wish». Его особенностью является передача интенсивности: «Mary wished to say something sensible, but knew not how». Ha этом примере можно видеть, что глагол «wish», соединённый с последующим глаголом речи «to say», помимо определения интенсивности, включает в себя также и эмотивный фактор. А именно два глагола придают данному предложению эмоциональность всего высказывания - ещё один, кстати, примечательный признак.

Необходимо отметить, что в шкала интенсивности носит субъективный характер, ведь она, как правило, зависит от непосредственного волеизъявления говорящего. Например: «I want to say a hundred things, and I can't find words to say them in. I never dreamed of this». Предложение, как видим, начинается с оборота «Я хочу сказать» как выражение намерения говорящего. Однако в дальнейшем мы наблюдаем всё возрастающую интенсивность за счёт отдельных семантических оттенков глаголов речи. Так, выражение «а hundred things» - это гиперболе, и она выразительна. Или другой случай: «yearn» при намерении что-либо произнести, противостоит нейтральному «want». И в этом тоже сказывается определённая степень интенсивности.

По идее, это тот достаточно редкий случай в лингвистике, когда намерение идёт вразрез с возможностью его исполнения. Можно сказать и так: «to say», как начало какого-либо сообщения не находит дальнейшей поддержки в восприятии слушающего. Однажды по этому поводу Жюль Верн скаламбурил: «Принято сообщение о том, чего не знать невозможно, а также о том, чему более верить вообще непозволительно» [4, с.34].

Известные современные лингвисты Т.М. Беляева и В.А. Хомяков пишут: «Некоторые английские глаголы речи имеют возможность декларировать интенциональность в большей или меньшей степени. Причём для этих глаголов характерно также и отсутствие семной связи (семантического согласования) с правосторонним компонентом, то есть подобная сочетаемость обусловлена экстралингвистически» [1, с.100-101]. И в дальнейшем учёные подтверждают своё мнение такими выражениями: «what I intend», «want to do» - «to go», «to say», «to know», что, по их утверждению, обусловлено ситуацией общения.

Семантический аспект глагола в инфинитиве «to tell», главным образом, состоит из сообщения, передаваемого от одного лица - к другому. Как верно замечает лингвист Е.М. Галкина-Федорук, «глаголы различных форм, включая их многочисленные категориальные признаки, следует отличать от вставных конструкций, пауз, многоточий, повторов, выражающие гамму чувств. Хотя они также могут и не указывать на мнение говорящего к высказываемым мыслям, не содержат в себе оценки сообщения, не называют его источники и не имеют связей с другим сообщением, никто не вправе отнять у них собственно речевых функций. Только в данном случае связанных с действием» [2, с.514-515]. Хотя широко известный учёный говорит о русском языке, это правило, на наше усмотрение, вполне приложимо и к глаголам речи романо-германской группы.

Действительно, в зависимости от характера и назначения конкретно поставленных задач, любое предложение в современном английском языке членится на взаимосвязанные между собою, но неравноценные по содержанию части: первая его часть - это исходный пункт в сообщении. В зависимости от цели высказывания, он известен либо неизвестен читателям, а потому и определяется конкретной ситуацией в контексте. В свя- 
зи с таким положением, можно указать и на дефиниции глагола речи «to tell» с указанием его инвариантов.

Объективно рассуждая, несколько основных значений уже выделено в современной лингвистике, в том числе и на примере англоязычной литературы. Однако в добавление к известному и ныне апробированному на практике материалу, мы возьмём на себя смелость в настоящей статье на основе уже предложенных дефиниций уточнить сферу употребления глагола to tell. Для справки: Сфера употребления = фактор.

Итак:

1. Коммуникационный фактор; передача оперативной информации;

2. Интеллектуальный фактор; выражение мысли;

3. Дипломатический фактор; передача скрытой (секретной информации);

4. Военный фактор. Приказы, команды;

5. Юридический фактор. Обсуждать, осуждать либо же трезво оценивать факты;

6. Собственно лингвистический фактор. Отличия, различия между фактами;

7. Литературоведческий фактор. Заявления, свидетельства, опора на что-либо. Например, сообщения в форме воспоминаний, дневниковых записей и т.д.

Ядро «номинативного поля», которое включает в себя прямые номинации концепта, связанного с глаголом «to tell», позволяет по аналогии c «to say» выделить такие лексико-семантические концепты: информирование, передача сообщений, приказы и т. д. по вышеприведённым нами дефинициям с учётом указанных факторов.

По квантитативным показателям, представленным в одной из работ Е.Н. Ширяева, «в ближнюю периферию глагола to tell входят около пятидесяти конституентов» [5, с.83]. И далее учёные перечисляет их семантические элементы. Это: глаголы relate, narrate, recount, rehearse,report, recite, которые в свою очередь объединены общей семой «сказывать, или рассказывать». По мнению Е. Ширяева, показательно для семантики этого глагола речи, что в отличие от «to say», здесь в особенности важна достоверность увиденного или услышанного. Другими словами, «to tell» - это не просто сообщение, передача некоей информации, она ещё и предусматривает наличие реципиента как свидетеля, очевидца тех или иных событий. Оценка же фактов приходит именно со стороны слушающего, то есть воспринимающего переданную ему информацию. Репрезентируют информацию такие глаголы, как «portray», «describe», «detail», «depict», «explain». Общей семой для них является значение «что-либо описывать средствами впечатления, объясняться помощью эмоции, одновременно с тем вдаваясь в подробности.
Например: «Let me see Martin Eden, and talk with him, and explain. He will understand and release you.» «No! no!» Ruth cried, starting up. «I do not want to be released. I love him, and love is very sweet. I am going to marry him - of course, if you will let me.» «We have other plans for you, Ruth, dear, your father and I...». Существо дела заключается в том, что при выборе соответствующих речевых ситуаций, необходимо каким-либо из них отдать предпочтение. Что же мы видим из приведённого примера? Установлен конкретный факт (замужество). То есть, решение принято, и говорящий выражает намерение в будущем, каким-нибудь образом изменить речевую ситуацию.

В дальнюю периферию входят такие глаголы и связанные с ними выражения, как «disembosom», «disbosom», «make a clean breast of», «get off one's» и т.д. с общей семой «говорить о чём-то наболевшем, а также желание высказаться, выплакаться, признаться в чём-то задушевном». А в крайнюю периферию входят глаголы «order», «command», «charge», «adjure», «direct», «dictate», «instruct» и некоторые другие. Общей семой для них является значение «направлять, командовать».

Тезаурус двух последующих глаголов («to speak» и «to talk»), по признанию ряда англоведов, является несколько меньшим. Соответственно немного уменьшается и объём материала о них в нашей статье. Так, глагол «to speak» характеризуется несколькими признаками, главными из которых являются активность и тесно связанная с ним семантически - волитивность. Что понимают под этими терминами? Первый характеризует активную личность, некий «пучок» или «сгусток энергии». Второй сознательно совершаемые им действия. Например, при употреблении «to speak» говорящий (или субъект) как бы сам способен контролировать исполнение событий. Поэтому «to speak» входит в различные группы со значениями:

1. Беседа на определённые темы;

2. Произнесение слов;

3. Описание фактов событий, явлений;

4. Разговор на каком-нибудь языке;

5. Ораторское искусство;

6. Утверждение (или подтверждение) каких-либо фактов, данных. Понятно, что сведения, исходящие от человека, носят признак одушевлённости.

В силу несколько меньшей сферы употребления «to speak», ближнюю, дальнюю и крайнюю периферии речепроизводства не вполне целесообразно дифференцировать. Ряд современных учёных полагает, что разница между ними не особенно и велика. В данном случае мы говорим о степени владения устной речью». Недаром определённая часть лингвистов, что «to talk», как бы продолжает концепт «to speak». Это тоже один из факторов устной речи, но обращённый в сторону продолжения 
беседы, дискуссии. Поэтому он включает в себя такие семантические элементы, как собственно разговор двух и более лиц, обсуждения чего-либо, а также просторечное (в переводе с английского: «болтать»). Впрочем, это ясно из самого названия. «То speak» означает «говорить», «сказать», a «to talk» - это прежде всего беседа.

Семантика «беседы», конечно же, шире, ведь она предполагает дискуссию по определённым вопросам. В этом смысле «to speak» является одноактным действием, тогда как «to talk» развивает и расширяет его. По этой причине мы уже имеем реальную возможность указать на дефиниции этого глагола, распределяя значения «to talk» по трём вышеуказанным перифериям. В таком случае в ближнюю периферию попадают следующие семантические компоненты, слова или словосочетания: «converse», «communicate», «rap or rap with exchange ideas», «speak with or to», «consult», «have a talk or little talk with», «check with», «confer», «parley», «discuss talk over palaver», «consider». И т.д. А объединены они значением «обмена мнениями, опытом». «Tо speak» и «to talk» также могут употребляться как просторечия. Так, под выражением о чём-либо болтать» почти всегда подразумевают нечто несущественное, пустяковое, не важное». Сопровождаются же такие выражения следующими языковыми единицами: «buzz», «gossip», «blab», «tell secrets or confidences», «circulate or spread rumors», «talk behind back dish the dirt» и т.п. Приведённое находит своё языковое выражение в семантическом компоненте «сплетничать». Совершенно очевидно, что этот компонент имеет отрицательную коннотативную окраску.

У глагола речи «to talk», как выясняется, есть одна отличительная черта. В ближнюю периферию в соответствии со стилистической пометой «просторечное», от собственно «беседовать» отпочковываются такие глаголы речи, как «babble», «tattle», «prate», «twattle», «twaddle», характеризующиеся обобщённым семантическим значением «лепетать, тараторить». Ближе к ним по той же шкале стоят «patter», «blather», «gabble», «drivel» co значением «молоть чепуху, говорить вздор». В ту же группу просторечных глаголов речи от «to talk» включают «mumble», «stammer», «mutter», «splutter», «stutter», «spit out sputter» с общим значением «бормотать, заикаться от чего-либо злобного, отвратного, цедить сквозь зубы».

В дальнюю периферию, включают такие слова или словосочетания, как «ореn one's mouth», «articulate», «speak», «enounce», «enunciate», «voice», «pronounce», «vocalize», «give voice or mouth to», «put in words». Heтрудно видеть, что эти слова образуют уже другую сферу употребления, а именно связанную с вокализмом. Ф. Данеш ещё в начале второй половины XX столетия высказал ценное предположение, относительно того, что некоторые английские глаголы речи (и «to talk» - в первую очередь), отдаляясь от своих номинативных значений, иногда могут приобретать признаки вокализма. Ф. Данеш писал, что это явление связано с длительностью произношения слов. И закрепил в лингвистике термин «таймирование» - фиксация направления тональности либо к началу, либо к концу ударных гласных. Поучительно при анализе английских глаголов речи продолжал свою мысль чешский учёный, что «в этом процессе учитываются такие параметры интенсивности, как разная степень компонентов высказываний. Другими словами: чем больше интенсивность, тем иллюстративно таймирование. Параметры интенсивности при беседах - это яркий критерий установления всевозможных средств тех значений, которые активно влияют на темпоральность всего выказывания целиком». В самом деле, «to talk» и его производные в дальней периферии могут и должны изучаться в самых различных аспектах - в грамматических, лексических, семантических, синтаксических, включая и фонологические явления. Потому что «лексико-семантическая микросистема со значением речевого высказывания объединена значением «произношения звуков, слов и слогов» [6, с.111-112].

Наконец, в зону крайней периферии входят глаголы или словосочетания: «reveal», «disclose», «give out», «divulge», «blurt out», «come out with», «let out», «let slip or drop», «put one's foot in one's mouth», «spill», объединённые значением «раскрыть секреты». А фразеологизм «put one's foot in one's mouth» означает «обидеть когонибудь, навредить кому-то».

Таким образом, от различных номинативных ядер образуются четыре центральных глаголов речи, главным образом и рассмотренных в настоящей статье. Отпочковывающиеся от них глаголы либо глагольные сочетания были нами распределены и по трём зонам: ближней, дальней и крайней. Каждая из них в определённой степени то приближалась, то, напротив, отдалялась от ключевого глагола, однако, семантическая наполняемость оставалась единой: предмет говорения или беседы всегда в центре внимания изучения глаголов такого типа.

\section{ЛИТЕРАТУРА}

1. Беляева Т.М., Хомяков В.А. Нестандартная лексика английского языка. Л.: Издательство Ленинградского университета, 1985, 136 с.

2. Галкина-Федорук Е.М. Современный русский язык. Часть II. Морфология. Синтаксис. М. МГУ, 1964, 638 с.

3. Дворник 0.Д. Функциональная категоризация глаголов говорения в современном английском языке. Автореф. дисс. ... докт. филол. наук. Белгород, 2003,27 c. 
4. Жюль Верн. С Земли на Луну. Роман. М.: Правда, 1985, 347 с.

5. Ширяев Е.Н. Глаголы речи, восприятия и мысли в роли разговорных модальных средств // Сокровенные смыслы: Слово. Текст. Культура. М.: Наука, 2004, c. 77-89.

6. Danes F. Functional sentence perspective and the organization of the text. Papers on functional sentence perspective. Prague: Academia, 1974, P. 106-128.

7. Vəliyeva N.Ç. Müxtəlif sistemli dillərdə nitq və təfəkkür feilləri ilə formalaşan frazeoloji vahidlər. Bakı, Azərbaycan Dövlət İqtisad Universitetinin mətbəəsi, $1999,104 \mathrm{~s}$.

(с) Ганбарова Нурлана Эльдениз гызы (giz.nur@bk.ru)

Журнал «Современная наука: актуальные проблемы теории и практики»
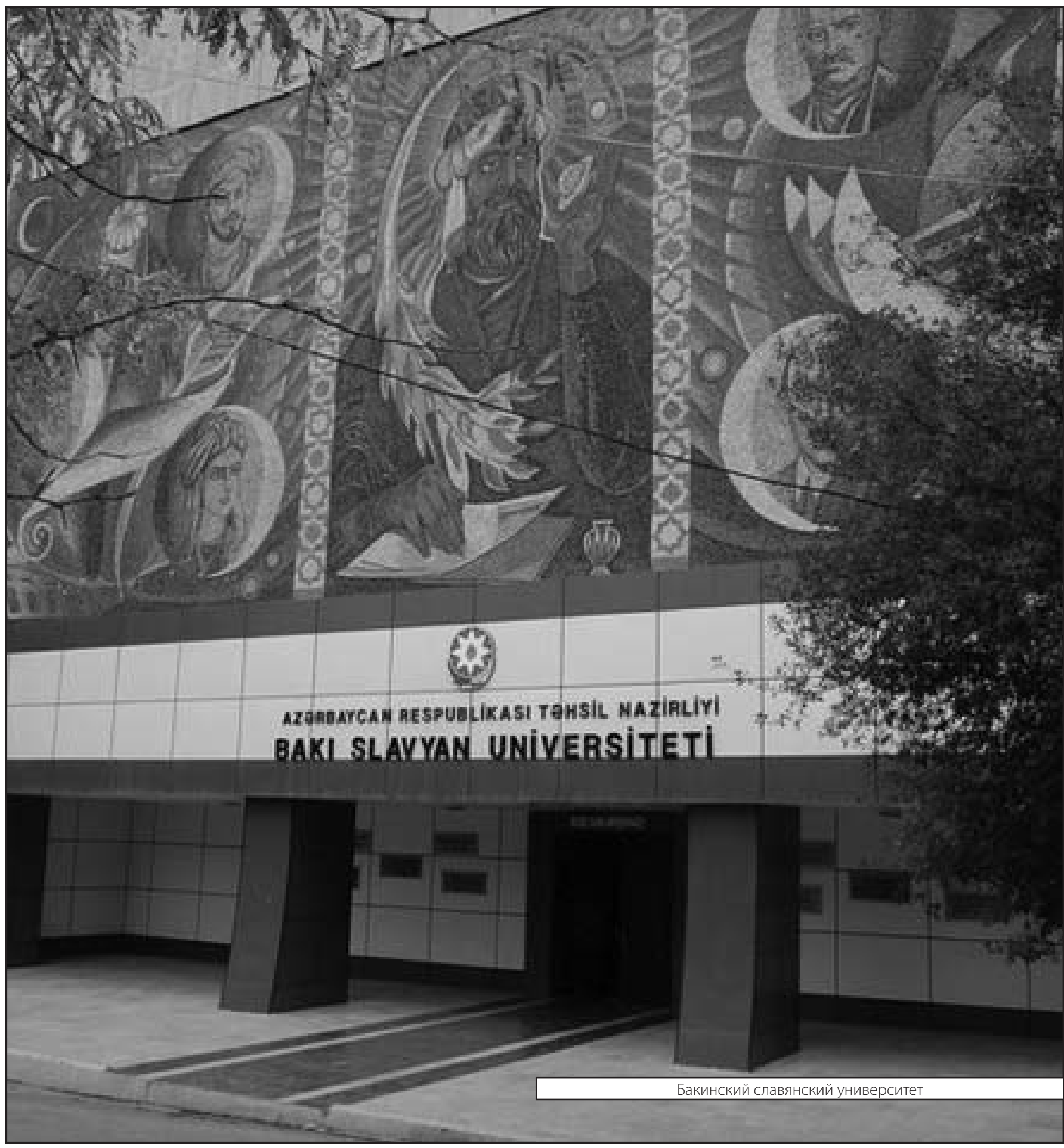